\title{
THE RELATION OF GREEN INFRASTRUCTURE AND TOURISM IN URBAN ECOSYSTEM
}

\author{
Inga Straupe, Līga Liepa \\ Latvia University of Life Sciences and Technologies, Latvia \\ inga.straupe@llu.lv
}

\begin{abstract}
Green infrastructure (GI) is a strategically planned network of high quality natural and semi-natural areas and provides a range of ecosystem services and protects biodiversity in urban settings. It is very important to increase understanding of the role of GI from a scientific and a socio-economic perspective. The main goal was to understand and assess the ways that tourists use from experiencing urban green infrastructure in the cities they visit. An interview questionnaire survey took place among tourists of the following countries and cities: Latvia (Riga and Jelgava) and Portugal (Lisbon and Faro). The questionnaire includes perception, psychological aspects and preferences, behavior and activities and general questions as well as biographical information about tourists. The study represents that no significant differences have been found between respondent groups in Latvia and Portugal. The results of the survey show that in future there is a need to improve the linkage between GI and social-cultural activities in cities. Therefore, studies for tourists' perceptions, preferences and uses of GI will provide the alternative management approaches for urban planning and tourism development in future.
\end{abstract}

Key words: green infrastructure, urban ecosystem, tourism.

\section{Introduction}

Over the last few decades the concept of green infrastructure (further - GI) has been popularized and integrated in urban planning documents, guidelines and its impact on development of tourism and residents have been analyzed. GI is a planned network of highly developed built and natural environments to facilitate clean air and water, carbon sequestration, pollination, preventing of floods and soil erosion etc. thus protecting biodiversity in urban settings. It also includes all green (parks, private gardens, agricultural fields, hedges, trees, woodlands and forests, green roofs, green walls etc.) and blue (freshwater, coastal and marine areas) spaces in and around our towns and cities (European Comission, 2013). Urban green spaces are providers of aesthetic images to cities by expressing values, beliefs and cultural trends in urban societies (James et al., 2009; Madureira et al., 2015).

In European cities, the idea of nature as a part of the infrastructure has long traditions from the start of the development of civilization (Cekule, 2010). The roles of urban green spaces vary widely with European cities and towns due to the differences in their environmental and socio-cultural backgrounds. A lot of common features can be found in the North European forest culture - particularly - in the eastern Baltic countries and Fennoscandia where this similarity is observed by the fact that forest is an important element of daily lives, it plays an important role in national economies, and it is a major element of the landscape (Tyrväinen et al., 2006; Bell, 2008). Green zones contribute to the recreational and aesthetic values and they are traditionally important (Gunnarsson \& Øhrstroom, 2007; Jim \& Chen, 2008). Urban forests differ in central Europe where land conversion processes have been profound. In Latvia, like in other countries of northern Europe, the human footprint on nature in the $20^{\text {th }}$ century and the subsequent alienation between people and nature did not have a very significant impact compared to other parts of Europe (Jankovska et al., 2014). GI is known to provide a range of ecosystem services; therefore, greater attention should be paid to the integration of the obtained ecological, economic and social benefits, particularly with regard to addressing the climate change issues (Elbakidze et al., 2018). It is very important to raise the awareness of the role of GI from a scientific and a socio-economic perspective and implement GI approaches with an emphasis on linking the environmental and social services. The main goal of the study was to understand and assess the ways the tourists use from experiencing urban green infrastructure in the cities they visit. The research hypothesis was the following: tourists are not much influenced by the presence of GI in their choice of destination.

\section{Materials and Methods}

This cross-cultural comparative research in Latvia and Portugal was carried out during the spring of 2015 with the task of collecting and analyzing data on tourists' uses of urban GI. The data from Portugal was collected by financial support from Cost action FP1204 Green Infrastructure approach: linking environmental with social aspects in studying and managing urban forests (Mietule, 2015). An interview questionnaire was prepared to clarify how the tourists perceive and use GI in the cities they have chosen to visit. The tourists of the following countries and cities (scale: one large and one medium): Latvia (Riga and Jelgava) and Portugal (Lisbon and Faro) were surveyed (Figure 1). 


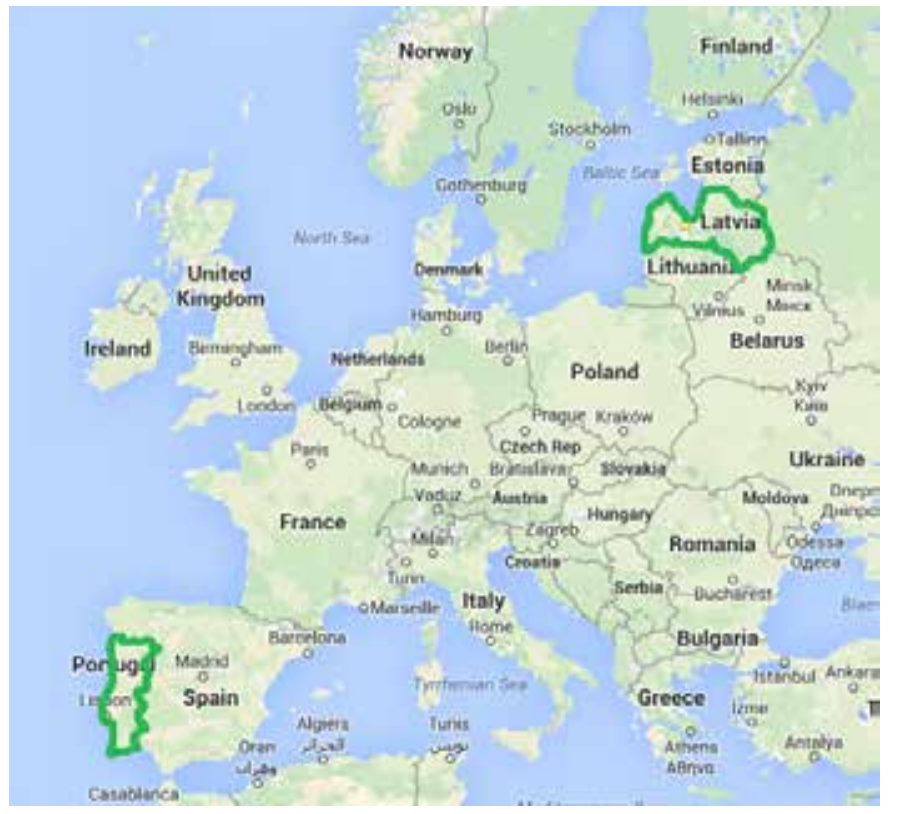

Figure 1. The study sites (source: www.googlemaps.com).

The study sites - Riga and Jelgava are located in Central part of Latvia. The territory of Riga is $307.17 \mathrm{~km}^{2}$, where green areas are approximately $28.0 \%$, water ecosystems - 15.6\%, and grey infrastructure (houses, buildings etc.) - 56.4\% (Riga today, 2018). Jelgava is located in central-south of Latvia, its territory is $62.32 \mathrm{~km}^{2}$. Green areas cover approximately $24 \%$ of the territory (Jelgava in short, 2018). Other two study sites in Portugal are located in Lisbon (Lisbon metropolitan area is $3015.24 \mathrm{~km}^{2}$ ) and Faro $\left(202.57 \mathrm{~km}^{2}\right)$. The marine climate is dominated by relatively hot summers and moist winter conditions with high precipitation (All about Portugal, 2017). All selected cities are urban tourism destinations. Moreover, one of them is the capital of the country. The main forms of tourism in Latvia's cities are architecture and culture, natural resources, sport and spa/ health, festivals and business, but in Portugal's cities - natural and cultural heritage, sea-sun and sports, business and cruise.

The questionnaire includes 28 questions, divided into five sections, related to: 1) perception; 2) psychological aspects and preferences; 3) behavior and activities; 4) general understanding of how tourists use GI in the city, what kinds of GI tourists like, how tourists prefer to use GI (open-ended types), and to what extent GI plays a role in tourists' choice of the cities to be visited (different categories were used: 'important', 'slightly important', 'irrelevant', 'not important' and 'do not know') and 5) biographical information about tourists (Terkenli et al., 2017). The questionnaire combines closed (yes/no, multiple-choice) and openended questions to investigate various dimensions of respondents' views (Tomićević, 2005). In total, approximately 50 questionnaires were completed for each study city, in total 200 respondents. Only foreign tourists were interviewed. Approximately 95\% of them were from European countries, many of them came from neighboring countries. Socio-demographic parameters of respondents: 1 ) gender: female $-50 \%$, male $-50 \%$; 2) age: $>25$ years $-30 \%$, 25-45 years $-47 \%$, 45-65 years $-17 \%,<65$ years $-6 \%$. The respondents from the group $<65$ years have had difficulties to communicate in English language; therefore, the proportion is low. The data were obtained in face-to-face interviews, and for the analysis descriptive statistics and correlation methods were used (Arhipova \& Bāliṇa, 2006).

\section{Results and Discussion}

In total, regarding the perception questions, the opinion in both countries was similar (Figure 2). The respondents in Riga described GI as territories of all green areas in the cities: urban forests, parks, squares, single trees and flower beds. Regarding perception questions, the majority of respondents perceived that GI should function for healthy living and this is the way of making a city more sustainable. Also, respondents from Jelgava acknowledged the correlation between GI and ecology issues. Other desirable GI things for respondents from Jelgava were green urban planning, proportional plan of parks and small green areas all around the city. However, GI represents the use of the natural space and the human space in symbiosis with landscape, enlightening that it is simply impossible to build a normal urban area without GI. Tourists in Lisbon identified green areas, parks and trees as the most characterized sites of GI. These respondents also suggested that GI improves water cycle, power 


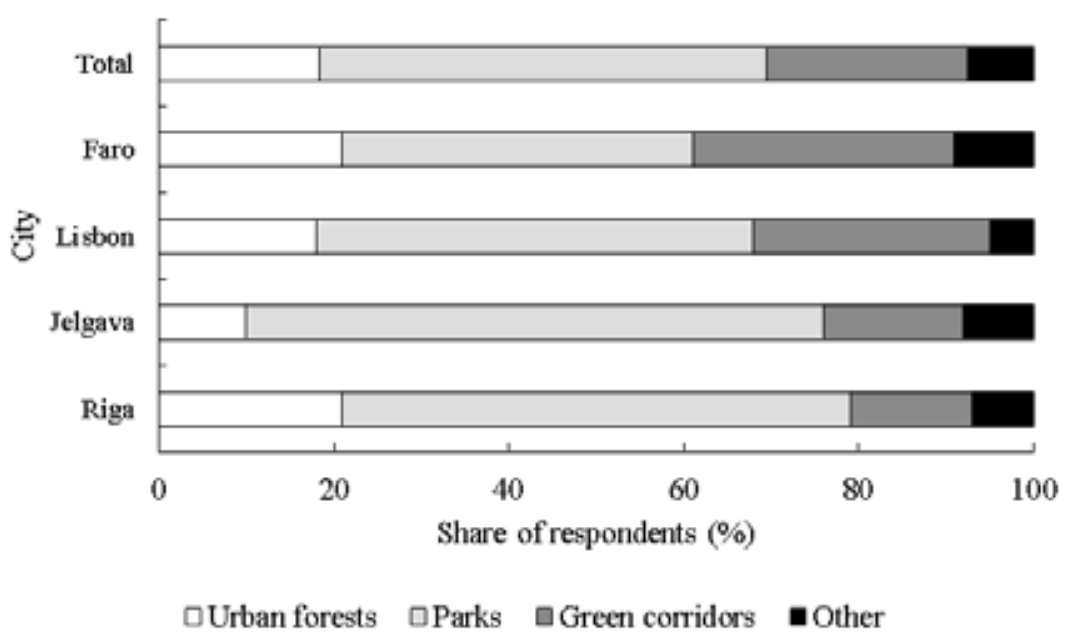

Figure 2. Most relevant green infrastructure sites for respondents in different cities.

saving and protects buildings. Also, respondents in Faro agreed that GI associates with plants and green spaces in urban area or zones related to nature, which preserves the urban environment from transport pollution. Also, similar associations with GI have been found in other countries, for example, Germany, United Kingdom, Austria, Italy, Netherlands, Belgium, Latvia and France (Cekstere \& Osvalde, 2013; Konijnendijk, 2008; Jankovska, Straupe, \& Panagopoulos, 2010). Respondents in Latvia stated that most important GI sites were parks (51\%) and urban forests $(18 \%)$. These findings are partly in line with those reported by Tyrväinen et al. (2006) who highlight the traditional importance of recreational and aesthetic aspects of urban forest, especially in the Nordic countries. As the forest is a major element of the landscape, it is essential in the national economy and peoples' everyday activities. However, the differences were observed in Portugal, where respondents prefer ecological corridors - tree, shrub or vascular plant lines or alleys, which improve the quality of urban landscape and its spatial structure. Also, respondents in Portugal argued that the distance between two recreational zones was more significant. This factor is explained by climatic conditions, for example, milder climate, low precipitation and average temperature.

The studies in other countries show that most tourists were familiar with the benefits of having urban forests in their preferred destination to enhance the enjoyment. City developers and urban forest managers of USA cities are constantly monitoring the condition of their urban forests, and this study provides feedback on how the visitors visualize urban forests to be structured (Andrada \& Deng, 2010).

The psychological preferences between cities varied due to different age groups. The respondents aged 45 and older preferred spending time in parks, but younger respondents chose various GI sites. This is explained by the fact that older respondents prefer light recreation activities on trails and paths. Nature of GI and landscape were the main factors determining its perceived value and suitability for recreational purposes. Each person's individual value of a forest used for these purposes is based on their conception of the beauty of the place and personal emotional longings (Gobster, 1996). Several studies show that climatic factors, accessibility, water resources and recreational facilities are significant. The most of visitors prefer outdoor recreation places which are near the water sources (Eskandari \& Ghadikolaei, 2013).

The majority of the respondents (78\%) referred GI as somewhat important for visiting a city (Figure 3). The tourism destination to Riga has been probably linked with different values. A similar study shows that GI has influenced the final destination of travel where only $11 \%$ of respondents were seeking for high valuable sites of GI, but 36\% - the choice was not related to GI at all. Examples of cities with famous green areas (New York's Central Park, Hyde Park in London etc.) illustrate how GI can play a significant role in attracting tourists (Konijnendijk, 2008).

Regarding the behavior and range of activities, they also reflected how important GI is and how it is understood in relation to tourists' actual use of GI and their plans to use it when visiting the cities as tourists (Figure 4). Most of the respondents declared that they use GI for walking (46\%) while fewer visitors use it for other types of activities, such as taking pictures (25\%), picnicking (17\%) and jogging (5\%).

The results also showed that during their trips more than half of respondents (60\%) plan to spend 1-2 hours in GI of cities, $21 \%$ of respondents - more time (2-5 hours), but $\sim 14 \%$ of respondents would spend only a few minutes and 4\% - 5-10 hours there (Figure 5). Thus, GI apparently represents a significant component of urban territories visited by tourists. 


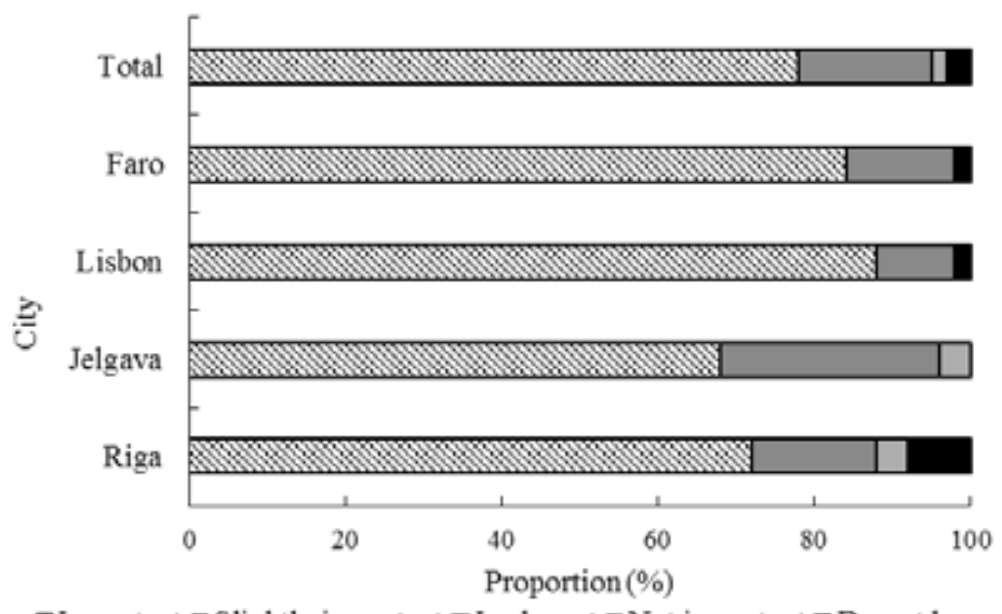

Figure 3. The respondents' attitude toward green infrastructure value in different cities.

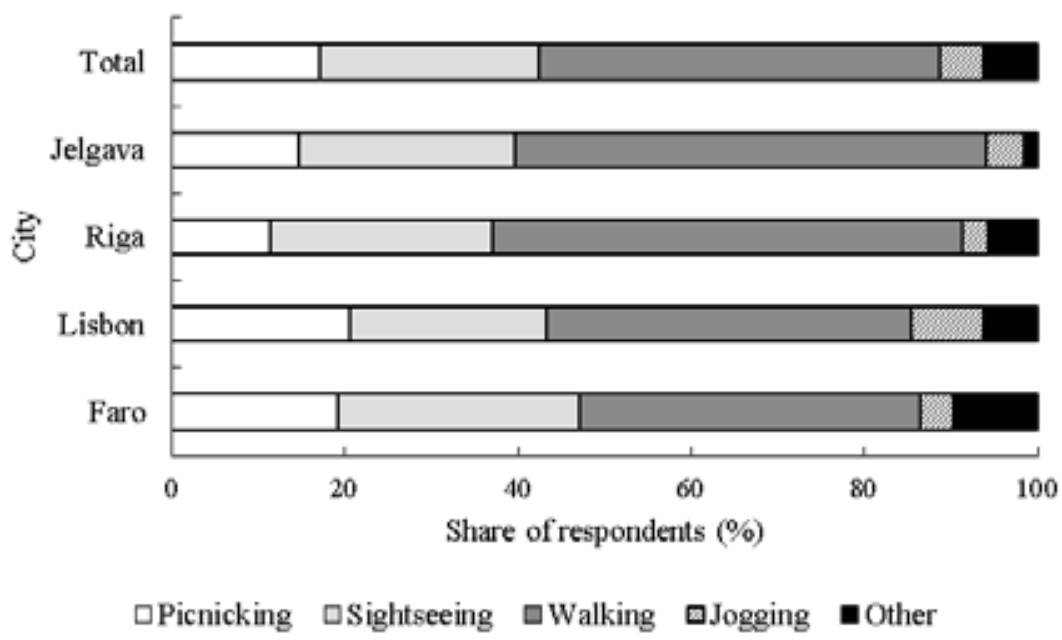

Figure 4. The respondents' attitude to recreational benefits of green infrastructure in different cities.

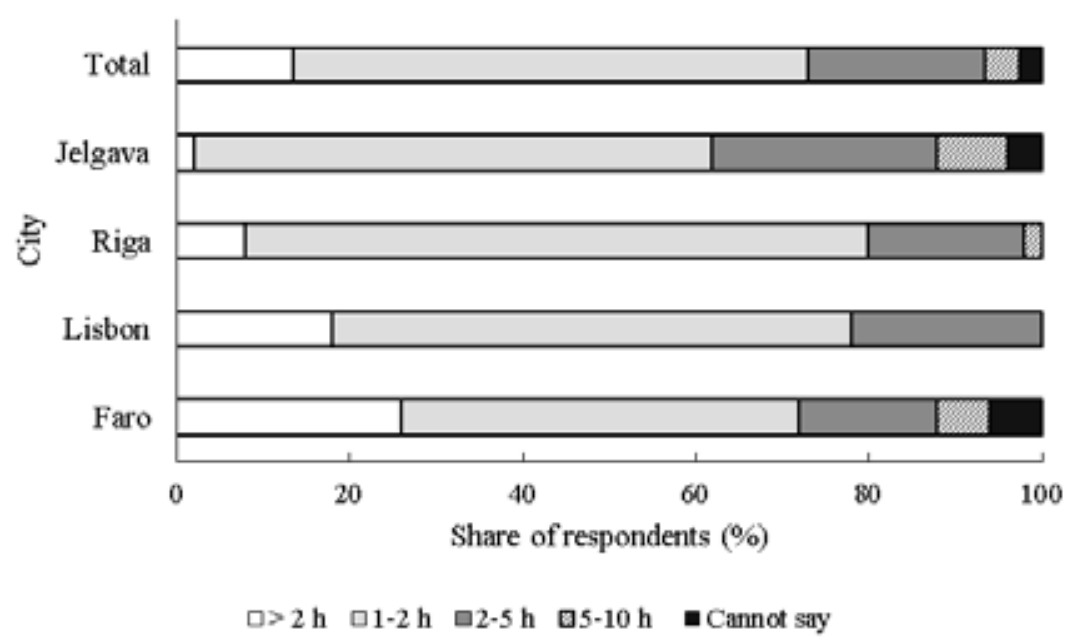

Figure 5. Duration of a typical green infrastructure site visit in different cities. 
Respondents from Latvia showed greater interest in urban GI than those from Portugal. However, analyzing the data of socio-demographics, a positive correlation between intention and interest in GI $(p=0.000)$ was found, which confirms that the more one is interested in GI, the higher the intention to use it. Although this study suggests if an individual has more interest in GI, he/ she will tend to pay for it, since the higher socio economic status, the more one is willing to pay for the use of GI (Terkenli et al., 2017), no significant correlations were observed between the status of the visitors and their readiness to pay for GI services. Likewise, no correlation was found between the city's geographic location and the tourists' willingness to pay for these services. The intention to use GI was the highest among the tourists travelling with friends, who also were reluctant to pay for services - while families showed a pronounced willingness to do it, but a low intention to visit them in the first place (Terkenli et al., 2017).

A similar study shows that respondent groups 'with higher and secondary education' expected to prefer those landscapes which have greater ecological and aesthetical value as well as higher biological diversity. Since ecological factors and social preferences of landscape are highly important, both of them can be integrated in the process of management, thus promoting natural succession processes, economical effectiveness, and the use of them by visitors (Jankovska et al., 2014).

\section{Conclusions}

1. GI fulfills similar quality values in elsewhere; therefore, this study represents that no significant differences have been found between respondent groups in Latvia and Portugal.

2. Results of the study showed that not all respondents are aware of the concept of 'Green Infrastructure', they mostly identified GI as parks, green corridors or urban forests; some respondents imagine it to be flower beds.

3. Many respondents enjoy visiting green spaces in cities mostly for relaxation and light physical activity - walking, but mostly - exploring the culture of the place.

4. Most of the respondents consider GI to be important to a city as well as the desire of tourists to visit a specific city although GI was not mentioned to be their major preference for sightseeing.

5. However, GI and sites of culture and history are often connected; the tourists usually combine the two when they visit the sights. The results of the survey show that in future there is a need to improve the linkage between GI and socialcultural activities in cities.

6. Therefore, such studies dealing with tourists' perceptions, preferences and uses of GI will provide the alternative management approaches for urban planning and tourism development in future.

\section{Acknowledgments}

We express our gratitude to Cost action FP1204 Green Infrastructure approach: linking environmental with social aspects in studying and managing urban forests for financial support, Zane Pastare (Mietule) and professor Thomas Panagopoulos from University of Algarve (Faro, Portugal) for providing background information for the research work.

\section{References}

1. All about Portugal. Retrieved March 12, 2018, from: https://www.visitportugal.com/en.

2. Andrada, R., \& Deng, J. (2010). Enjoying green cities: assessing visitors attitudes and preferences for urban forests in Washington, DC. In Proceedings of the 2010 Northeastern Recreation Research Symposium GTR-NRS-P-94, April 2010 (pp. 168-174).

3. Arhipova, I., \& Bāliņa, S. (2006). Statistika ekonomikā un biznesā: risinājumi ar SPSS un MS Excel (Statistics for economics and business: solutions by SPSS and MS Excel). Riga, Datorzinību centrs (in Latvian).

4. Bell, S. (2008). Design for outdoor recreation. Abingdon, Taylor \& Francis.

5. Cekstere, G., \& Osvalde, A. (2013). A study of chemical characteristics of soil in relation to street trees status in Riga (Latvia). Urban Forestry \& Urban Greening, 12(1), 69-78. DOI: 10.1016/j.ufug.2012.09.004.

6. Cekule, M. (2010). Rīgas telpiskās struktūras analīze, izmantojot ǵeogrāfiskās informācijas sistēmas (Riga's city spatial structure analysis based on geographical information system). Doctoral thesis, University of Latvia, Riga, Latvia. (in Latvian).

7. Elbakidze, M., Angelstam, P., Dawson, L., Shushkova, A., Naumov, V., Rendenieks, Z., Liepa, L., Trasūne, L., Ustsin, U., Yurhenson, N., \& Uhlianets, S. (2018). Towards Functional Green Infrastructure in the Baltic Sea Region: Knowledge Production and Learning Across Borders. In: Perera, A.H., Peterson, U., Gullermo, M.P., \& Iverson, L.R. (Ed.) Ecosystem Services from Forest Landscapes (57-87). Springer, Cham. DOI: 10.1007/978-3-319-74515-2_10. 
8. Eskandari, S., \& Oladi Ghadikolaei, J. (2013). Assessment of ecotourism potential of urban forest parks based on effective factors in outdoor recreation, a case study: Sorkhe Hesar Forest Park. World Applied Sciences Journal, 27(8), 950-960.

9. European Commission. Green infrastructure (GI) - enhancing Europe's Natural capita, COM (2013) Brussels, 6.5.2013. Retrieved March 12, 2018, from: http:/ec.europa.eu/environment/nature/ecosystems/ docs/green_infrastructures/1_EN_ACT_part1_v5.pdf.

10. Gobster, P.H. (1996). Forest aesthetics, biodiversity, and the perceived appropriateness of ecosystem management practices. In: Defining Social Acceptability in Ecosystem Management. M.W. Brunson, L.E. Kruger, C.B. Tyler, S.A. Schroeder (eds). A workshop proceedings, (77-97).

11. Gunnarsson, G., \& Øhrstroom, E. (2007). Noise and well-being in urban residential environments: the potential role of perceived availability to nearby green areas. Landscape and Urban Planning, 83, 115126. DOI: 10.1016/j.landurbplan.2007.03.003.

12. Jankovska, I., Straupe, I., Brumelis, G., Donis, J., \& Kupfere, L. (2014). Urban forests of Riga, Latviapressures, naturalness, attitudes and management. Baltic Forestry, 20(2), 342-351.

13. Jankovska, I., Straupe, I., \& Panagopoulos, T. (2010). Naturalistic Forest Landscape in Urban Areas: Challenges and Solutions. In: Jha M (ed.) Latest trends on urban planning and transportation, 3rd WSEAS International Conference on Urban Planning and Transportation (UPT '10), Published by WSEAS Press, pp. 21-26.

14. Jim, C.Y., \& Chen, W.Y. (2008). Assessing the ecosystem service of air pollutant removal by urban trees in Guangzhou (China). Journal of Environmental Management, 88(4), 665-676. DOI: 10.1016/j. jenvman.2007.03.035.

15. Jelgava in short. Retrieved March 12, 2018, from: http://www.jelgava.lv/en/city/jelgava-in-short/.

16. James, P., Tzoulas, K., Adams, M.D., Barber, A., Box, J., Breuste, J., Elmqvist, T., Frith, M., Gordon, C., Greening, K.L., \& Handley, J. (2009). Towards an integrated understanding of green space in the European built environment. Urban Forestry \& Urban Greening, 8(2), 65-75. DOI: 10.1016/j.ufug.2009.02.001.

17. Konijnendijk, C.C. (2008). The forest and the city: the cultural landscape of urban woodland. Berlin, Springer Verlag.

18. Madureira, H., Nunes, F., Oliveira, J.V., Cormier, L., \& Madureira, T. (2015). Urban residents' beliefs concerning green space benefits in four cities in France and Portugal. Urban Forestry \& Urban Greening, 14(1), 56-64. DOI: 10.1016/j.ufug.2014.11.008

19. Mietule, Z. (2015). Zal̦ās infrastruktūras sociālā loma pilsētās Latvijā (The social role of Green infrastructure in cities in Latvia). Master thesis. Latvia University of Agriculture, Jelgava, Latvia. (in Latvian).

20. Riga today. Municipal Portal of Riga. Retrieved March 12, 2018, from: https://pasvaldiba.riga.lv/LV/ Channels/Riga_today/default.htm.

21. Terkenli, T.S., Bell, S., Živojinović, I., Tomićević-Dubljević, J., Panagopoulos, T., Straupe, I., Toskovic, O., Kristianova, K., Straigyte, L., \& O’Brien, L. (2017). Recreational Use of Urban Green Infrastructure: The Tourist's Perspective. In: Pearlmutter, D., Calfapietra, C., Samson, R., O’Brien, L., Krajter Ostoić, S., Sanesi, G. and Alonso del Amo, R. (Ed.). The Urban Forest: Cultivating Green Infrastructure for People and the Environment (191-216). Berlin, Springer Verlag.

22. Tomićević, J. (2005). Towards Participatory Management: Linking People, Resources and Management. A Socio-Economic Study of Tara National Park. Doctoral thesis. Culterra, Schriftenreihe des Instituts für Landespflege der Albert-Ludwigs-Universität Freiburg, Germany.

23. Tyrväinen, L., Gustavsson, R., Konijnendijk, C., \& Ode, Å. (2006). Visualization and landscape laboratories in planning, design and management of urban woodlands. Forest Policy and Economics, 8(8), 811-823. DOI: 10.1016/j.forpol.2004.12.005. 